\title{
Andar a par: saúde mental, psiquiatria e cuidados de saúde primários
}

Paula Teresa Carvalho*

"Não há saúde sem saúde mental"

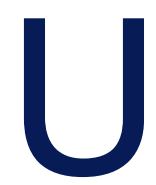
ma frase, uma afirmação feliz que condensa algo de óbvio e consensual e que já ouvimos e lemos até à exaustão, em documentos oficiais, em congressos e encontros, em directrizes da OMS e da União Europeia e por aí adiante.

Aliás, nunca como agora, com a investigação e o conhecimento produzidos pela neurociência, esta noção da interacção mente/corpo e do impacto dos aspectos relacionais, emocionais e afectivos no sentir corporal e na nossa narrativa biológica foi tão clara.

Mas, e na prática? De que modo esta dimensão transversal da saúde mental se traduz na clínica e na estruturação dos cuidados de saúde?

Há anos, muitos, que temos conhecimento de trabalhos e de investigação que demonstram a importância dos cuidados de saúde primários e da articulação com os serviços de psiquiatria nas questões da saúde mental. A nível nacional temos conhecimento de experiências e de projectos sólidos e válidos nestas áreas, temos um Plano Nacional de Saúde Mental e a saúde mental surge nos programas prioritários do Plano Nacional de Saúde... sempre com destaque para a articulação de cuidados... Porém, na realidade, o panorama está longe de ser satisfatório, antes pelo contrário.

Haverá muitas formas de olhar, de pegar no assunto e de tentar compreender o porquê das dificuldades. Uma delas é pegar a partir das pessoas, pois são as pessoas que materializam os projectos e escolho partir daí e da minha própria experiência profissional.

Há 21 anos, recém-especialista em psiquiatria, vim iniciar uma consulta de psiquiatria de ligação no então

*Psiquiatra, Grupanalista, fundadora e ex-coordenadora do Serviço de Psiquiatria e Saúde Mental do actual Centro Hospitalar do Oeste.
Centro Hospitalar das Caldas da Rainha. Era a única psiquiatra no hospital e, infelizmente pouco tempo depois, com o desaparecimento do psiquiatra que trabalhava no Centro de Saúde, fiquei a ser a única a nível institucional, numa área de influência que incluía os concelhos de Caldas da Rainha, Óbidos, Bombarral e Peniche.

Trazia na bagagem o internato da especialidade feito no Hospital Miguel Bombarda, na equipa de Sintra, chefiada pelo Dr. João Sennfelt. Trazia, portanto, conhecimento e prática dum modelo funcional em que a articulação e o trabalho em grupo com os médicos de família, de saúde pública e com outras estruturas comunitárias foi parte estrutural da formação como psiquiatra. ${ }^{1}$

Falo disto, pois penso que a experiência e a formação são fundamentais na construção do saber e da identidade clínicas, em termos de prática médica. Independentemente dos normativos e do conhecimento teórico, a experiência que desenvolvemos e que observamos nos outros é determinante na nossa construção como profissionais de saúde.

Foi, assim, possível partir para um trabalho de envolvimento com os médicos de família e com outras estruturas comunitárias, no sentido de criar respostas e abordagens referentes às necessidades das pessoas nestas matérias de saúde. E não falo só das necessidades dos pacientes e famílias e das complexidades multifactoriais e multidisciplinares inerentes às coisas da saúde mental; falo das minhas próprias, das dos colegas e das de outras pessoas, outros técnicos, de diferentes instituições e estruturas comunitárias, pois que sozinhos e cada um por si nos sentíamos incapazes de responder minimamente ao que nos era solicitado, sentindo frequentemente que todo o esforço se perdia na falta de recursos e de respostas adequadas e articula- 
das, criando um sentimento de exaustão e de frustração. Uma boa articulação surgia como sinónimo de rentabilização de recursos, de melhores respostas, de melhores resultados e de maior satisfação para todos os envolvidos.

Foi, assim, possível acontecer um protocolo de colaboração entre o hospital e os centros de saúde da região que incluía reuniões e consultas ombro-a-ombro com os médicos de família, nas instalações dos centros de saúde, e mais tarde até via skype, com o médico de família e paciente dum lado e o psiquiatra do outro.

Foi, assim, possível acontecer um núcleo de intervenção na área da saúde mental, o NIASM, numa parceria que cresceu para mais de vinte parceiros comunitários e onde se desenham planos alargados de intervenção terapêutica numa perspectiva biopsicossocial.

Foi, assim, possível organizar seminários anuais e vários workshops sobre saúde mental.

Foi, assim, possível fazer na prática muitas das coisas que "vinham nos livros", tentar replicar boas práticas desenvolvidas por outros e adaptar modelos à realidade e aos recursos locais.

Foi possível, assim, porque na altura houve gente, pessoas no terreno, nas chefias e nas administrações que foram capazes de perceber e de estar disponíveis para apostar, apoiar, investir num trabalho de grupo criativo, adaptativo, colaborativo. Porque fazia sentido e era necessário que fosse assim. Porque funcionava e os números apareciam. Porque se tentava desenvolver uma matriz e um trabalho de equipa, entre pares, com supervisão e intervisão clínicas, em que o grupo, a própria equipa desempenhava a função de supervisor e de gestor de caso(s). Em que, mantendo a dimensão formativa e de formação em contexto de trabalho, se procurava encontrar respostas transdisciplinares, numa perspectiva em que o todo é superior à soma das partes, sem que a responsabilidade e a especificidade de cada um fossem diluídas ou desleixadas.

Escolhi pegar nas pessoas, pois trabalhar em saúde implica trabalhar com pessoas e para as pessoas, sendo que as relações humanas são sempre coisas complexas. Hierarquias, estatutos, poder, interesses, estilos, objectivos, competições, culturas, formação, preconceitos, medos, alianças, resistências, ambições... enfim, uma panóplia multifactorial que complexifica e in- terfere no funcionamento e nas dinâmicas relacionais de grupos e instituições. Mas são sempre pessoas, as pessoas que duma forma ou de outra fazem as diferenças. Para o bem e para o mal.

Sendo complexa a criação duma dinâmica relacional de trabalho saudável e funcionante, em que os membros do grupo/organização, da equipa, sintam que sem perder a sua individualidade e capacidade de pensar e fazer o grupo lhes devolve um sentimento de pertença e de realização, assume particular importância o modo como as instituições aplicam e desenvolvem normativos e regras de funcionamento, definem objectivos e valorizam determinadas práticas em detrimento de outras. Quantas vezes boas ideias, bons projectos falham porque falharam o envolvimento e a preparação adequadas das pessoas que teriam que o pôr e manter em prática? Quantas vezes não surgem clivagens fatais entre aquilo que é definido como objectivo principal dum determinado projecto ou plano de intervenção e o modo e/ou condições como é implementado? Tão verdade como não se fazerem omeletes sem ovos é não bastar haver ovos para se fazerem omeletes.

Falemos, então, de algumas destas clivagens: "Não há saúde sem saúde mental”. No entanto, por exemplo no que respeita a indicadores de saúde, os de saúde mental são insuficientes e desadequados... Ora, como actualmente se promove o trabalho por objectivos, se não há indicadores mensuráveis, como se faz?... Deixa de se cuidar e de valorizar esta área? Não se discute a importância de existirem indicadores que permitam medir, comparar e avaliar as práticas individuais e institucionais. No entanto, parece que perversamente deixaram de ser um instrumento de avaliação para passarem a ser o fim em si, estimulando um funcionamento acrítico, burocrático, desligado da realidade das pessoas que temos à frente e das suas necessidades. E se o trabalho for valorizado apenas através dos indicadores de resultados, se o tempo e o investimento nas consultas, numa boa anamnese, na compreensão das vicissitudes bioexistenciais e vivenciais dos pacientes, nos processos de articulação, de discussão, de supervisão e de intervisão clínicas, não for contabilizado, é natural que a disponibilidade para envolvimento nestes processos vá diminuindo ou mesmo desapareça... Saber fazer um diagnóstico médico correcto é fundamental, mas é pouco para se ser bom médico e fazer boa Medicina... e 
todos sabemos isto. Como também sabemos que nesta área, como noutras na Medicina, a prescrição farmacológica é uma parte do plano terapêutico, mas não a exclusiva... Não deveriam ser criados também indicadores de processo? E não se deveria priorizar de modo objectivo, de algum modo quantificável, um funcionamento interpares entre os diferentes níveis de cuidados de saúde? Que grau de autonomia, de espaço pensante, de escolha e de crítica construtiva estamos dispostos a perder e a alienar, enquanto indivíduos e enquanto grupo, em nome do cumprimento da norma só pela norma mesmo, quando acrítica, ela surge contrária ao que a evidência, o conhecimento e a prática nos ensinam?... E sem sentir que somos todos descartáveis e manipuláveis?...

Muitos doentes com depressão se queixam de que a sua doença e o seu sofrimento não são suficientes e objectivamente mensuráveis, reforçando como tantas vezes se sentiram incompreendidos e recriminados, agra- vando a vivência depressiva. Brevemente, a depressão ocupará o primeiro lugar como causa de incapacidade por doença... Não se mede, mas lá que existe, existe... e não estamos a falar só da depressão...

E então? Temos anos de teorias... escolhemos o quê? Andar a par ou fecharmo-nos cada vez mais dentro das nossas caixinhas?

\section{REFERÊNCIAS BIBLIOGRÁFICAS}

1. Rebelo MF, Gonçalves MJ, Bolina FM. A $3^{\text {a }}$ face da Lua: saúde mental em cuidados de saúde primários. Loures: Lusodidacta; 2014. ISBN 9789898075376

\section{CONFLITOS DE INTERESSE}

A autora declara não ter qualquer conflito de interesses.

ENDEREÇO PARA CORRESPONDÊNCIA

paulatcarvalho@gmail.com

Artigo redigido ao abrigo do acordo ortográfico anterior a 1990. 